\title{
Serum level of vitamin $D$ in preterm infants and its association with premature-related respiratory complications: a case-control study
}

\author{
Hasan Boskabadi ${ }^{1}$, Gholamali Mamoori ${ }^{2}$, Seyedeh Fatemeh Khatami ${ }^{2}$, Raheleh Faramarzi ${ }^{3}$
}

${ }^{1}$ MD of Neonatology, Associate Professor, Department of Pediatric, Faculty of Medicine, Mashhad University of Medical Sciences, Mashhad, Iran

${ }^{2}$ MD of Neonatology, Professor, Department of Pediatric, Faculty of Medicine, Mashhad University of Medical Sciences, Mashhad, Iran

${ }^{3}$ MD of Neonatology, Assistant Professor, Department of Pediatric, Faculty of Medicine, Mashhad University of Medical Sciences, Mashhad, Iran

\section{Type of article: Original}

\begin{abstract}
Background and aim: Prematurity and related problems, especially respiratory distress, are one of the main challenges for neonatal medicine. The aim of this study was to compare vitamin D levels in preterm infants with, and those without respiratory distress.

Methods: This case-control study was conducted in Ghaem and Emam Reza Hospitals in Mashhad (Iran) from 2015 to 2016. In this study, we examined 160 preterm infants weighing less than 2000 grams and born at less than 34 weeks' gestation. Serum vitamin D levels were measured in preterm infants without- and those with respiratory distress, and their mothers. Neonatal characteristics, including age, sex, birth weight, gestational age, Apgar score and needs for oxygen, resuscitation, ventilation and surfactant were documented. The data were analyzed using SPSS version 16.0.

Results: Means serum level of maternal vitamin D in control and case groups were $16.66 \pm 14.29 \mathrm{ng} / \mathrm{dl}$ and $21.23 \pm 15.19 \mathrm{ng} / \mathrm{dl}$, respectively $(\mathrm{p}=0.029)$. In addition, mean serum level of neonatal vitamin $\mathrm{D}$ in control and case groups were $11.69 \pm 8.66 \mathrm{ng} / \mathrm{dl} 17.9 \pm 12.55 \mathrm{ng} / \mathrm{dl}$, respectively $(\mathrm{p}=0.001)$. Vitamin $D$ levels in premature neonates without respiratory distress and their mothers were significantly different from other preterm neonates with respiratory distress $(\mathrm{p}=0.029)$. There was a direct correlation with neonatal and maternal vitamin $\mathrm{D}$ levels $(\mathrm{r}=0.713, \mathrm{p}=0.001)$. The duration of hospitalization $(\mathrm{p}=0.001)$, gestational age $(\mathrm{p}=0.073)$, birth weight $(\mathrm{p}=0.001)$, one- and $(\mathrm{p}=0.001)$ five- minute $(\mathrm{p}=0.001)$ Apgar scores and head circumference $(\mathrm{p}=0.002)$ had significant relation with vitamin D levels in neonates. Death $(12.5 \%)$ and pneumothorax $(7.5 \%)$ were the main complications among cases with respiratory distress.

Conclusion: According to the results of present research, neonatal vitamin D levels have a significant association with respiratory distress syndrome and maternal vitamin D levels.
\end{abstract}

Keywords: Vitamin D; Infants, Premature; Respiratory Distress Syndrome, Newborn

\section{Introduction}

Respiratory distress syndrome (RDS) is a common problem and underlying cause of death in premature infants (born before the 37th week of pregnancy) which result from an insufficient production of pulmonary surfactant. In the United States, RDS affects approximately 10 percent of premature newborns each year (1). Male sex, white race, low birth weight, lower gestational age, delivery between 34 and 36 weeks of gestation and elective labor induction are the main risk factors for RDS (2). Babies' lungs begin to develop in the embryo and continue until the age of three. Fetal lung maturity occurs with differentiation of type II pneumocytes which show a marked depletion

\section{Corresponding author:}

Dr. Raheleh Faramarzi, Department of Pediatric, Faculty of Medicine, Mashhad University of Medical Sciences, Mashhad, Iran. Tel: +98.5138433028, Email: rahele.faramarzi@yahoo.com

Received: July 12, 2017, Accepted: September 03, 2017, Published: January 2018

iThenticate screening: September 03, 2017, English editing: December 12, 2017, Quality control: December 15, 2017 This article has been reviewed / commented by four experts

(C) 2018 The Authors. This is an open access article under the terms of the Creative Commons Attribution-NonCommercialNoDerivs License, which permits use and distribution in any medium, provided the original work is properly cited, the use is non-commercial and no modifications or adaptations are made. 
in glycogen stores, and surfactant production begins. Therefore, premature birth can cause RDS because of insufficiency of surfactant production $(3,4)$. Vitamin D is a prohormone that has a significant role in calcium metabolism (5). Since vitamin D has many biological functions in metabolism, requirement for vitamin D is increased during pregnancy. The fetus is unable to produce endogenous $25-\mathrm{OH} \mathrm{D}$ and becomes completely dependent on transfer from the mother (6). As transplacental transmission of vitamin D predominantly happens during the third trimester of pregnancy (7), preterm infants are at the higher risk of vitamin D deficiency (8). In addition, $1.25-\mathrm{OH} \mathrm{D}$ is synthesized in the kidneys of the fetus and there is no $1.25-\mathrm{OH} \mathrm{D}$ production in the fetus with renal agenesis $(7,9)$. The effects of vitamin D on lung development is an important issue in recent research (10-12). Previous studies showed that maternal vitamin D deficiency is associated with reduced fetal development, weight loss and increase in the risk of preterm birth, which consequently resulted in RDS and increase in bronchopulmonary dysplasia (BPD) (13). On the other hand, the hypothesis of the role of vitamin D in embryogenesis, cell growth and differentiation and lung development has been considered (13). Early observations confirm that vitamin D deficiency contributes to the respiratory distress syndrome in small preterm infants, it is also called rachitic respiratory distress $(3,4)$. Impact of vitamin D on the alveolar type II cell, fibroblast proliferation, surfactant synthesis and alveolarization were revealed in animal and laboratory studies (13). Also, in human studies, the impact of vitamin D on production of pulmonary surfactant has been demonstrated (14). So, it is proposed that vitamin D deficiency may act as predisposing factor for pulmonary diseases in preterm infants. Although major steps have been taken to improve our knowledge on the pathophysiology of RDS, it is still considered a significant clinical complication among premature infants (2). Given the role of vitamin D in respiratory health, to date, there has been very little research on the incidence of vitamin D deficiency in preterm infants and this emphasizes the necessity for more prospective studies. The overall aim of this study was to assess the serum level of vitamin D in preterm infants and to determine its possible association with premature-related respiratory complications.

\section{Material and Methods}

\subsection{Study design and participants}

This prospective, case-control study was performed on preterm infants admitted to the neonatal intensive care unit (NICU) and neonatal wards of Ghaem and Emam Reza Hospitals affiliated to Mashhad University of Medical Sciences, Iran in 2015 and 2016. One hundred sixty preterm infants with birth weight less than 2000 grams and gestational age less than 34 weeks, along with their mothers, were consecutively included in the study. The cases were divided into two groups; those without respiratory distress (control group $=80$ cases) and those with it (case group $=80$ cases). Neonates were included in case group according to RDS score system comprising the clinical signs: respiratory rate, grunting, color, retractions, breathing sounds on auscultation and oxygen requirement (15). Neonates in the control group were premature infants who were admitted to the labour ward or in neonatal wards for non- respiratory causes. Infants with apparent congenital anomalies and those born from complicated pregnancy were excluded.

\section{2. Sample size}

The sample size was calculated in two groups using the following formula. Considering a power of $80 \%$ and an alpha error of 0.05 , the sample size assumption for this study was 75 neonates. Considering loss to follow-up, this number was adjusted to 80 neonates in each study group: $\mathrm{n}=(\mathrm{u}+\mathrm{v})^{2}\left(\mathrm{~s}_{1}{ }^{2}+\mathrm{s}_{2}{ }^{2}\right) /\left(\mathrm{m}_{1}-\mathrm{m}_{2}\right)^{2}$

\section{3. Clinical characteristics}

Demographic data including gestational age, birth weight, sex, information from neonates examination including Apgar score (collected by pediatricians in delivery room), the needs for resuscitation, surfactant and oxygen administration during mechanical ventilation, cause and length of hospitalization, symptoms of respiratory distress, characteristics of mothers including age and delivery type were collected in a questionnaire by a physician. Also, complications during admission and in-hospital mortality in neonates were recorded. Pneumothorax was diagnosed by chest radiograph (CXR), sepsis diagnosis was based on culture and in meningitis diagnosis was based on CSF parameters and CSF culture.

\section{4. Vitamin D Measurement}

Two milliliters of whole blood from infants and their mothers were collected and preserved in $0-4$ degrees centigrade. Samples were sent to the hospital laboratory for evaluation of vitamin D level. Serum level of vitamin D was measured using enzyme linked immunosorbent assay (ELISA), using an ELISA reader device (RT2100C, Germany). The patients were divided into four groups according to their vitamin D level: severe deficiency $(10 \mathrm{ng} / \mathrm{ml})$, moderate deficiency $(10-20 \mathrm{ng} / \mathrm{ml})$, mild deficiency $(20-30 \mathrm{ng} / \mathrm{ml})$ and normal level $(30 \mathrm{ng} / \mathrm{ml})(16)$. 
http://www.ephysician.ir

\subsection{Ethics of research}

The study was approved by the ethical committee of Mashhad University of Medical Sciences, Mashhad, Iran (number: 940434). The Informed consent was obtained from the children's parents.

\section{6. Statistical analysis}

Descriptive statistics are presented as mean \pm standard deviation and percentages. Categorical variables were compared using chi-square or Fisher's exact tests. The independent t-test and the Mann-Whitney U test were used for comparing means of variables. Due to non-homogeneity of some variables between the two groups, multiple linear regression analysis was used to assess the associations between neonatal and maternal blood vitamin D levels taking into account possible confounding variables including birth weight and gestational age. Correlation between vitamin D level and number of ventilated days were analyzed by Pearson correlation coefficient. Statistical analyses were performed using SPSS version 16.0, and P value less than 0.05 was considered statistically significant.

\section{Results}

During a one-year period, 160 premature neonates were included in the study, eighty without respiratory distress syndrome (control group) and eighty with it (case group). There were 83 (51.9\%) males and 77 (48.1\%) females. The male to female ratio in the control and case groups were 0.78 and 1.5 , respectively. The clinical and laboratory characteristics of the two groups are shown in Table 1. After controlling for potential confounding factors including gestational age and birth weight vitamin D level was significantly higher in control group. The means of maternal vitamin D level in control and case groups were $16.66 \pm 14.29 \mathrm{ng} / \mathrm{dl}$ and $21.23 \pm 15.19 \mathrm{ng} / \mathrm{dl}$, respectively $(\mathrm{p}=0.029)$, and also the mean of neonatal vitamin D level in control and case groups were $11.69 \pm 8.66 \mathrm{ng} / \mathrm{dl} 17.9 \pm 12.55 \mathrm{ng} / \mathrm{dl}$, respectively $(\mathrm{p}=0.001)$ (Table 1$)$.

Table 1. Clinical and laboratory characteristics of premature neonates with (case group) those without respiratory distress (control group). Data are expressed as mean \pm SD and percentage

\begin{tabular}{|l|l|l|l|}
\hline Variables & Case, $(\mathrm{n}=80)$ & Control, $(\mathrm{n}=80)$ & $\mathrm{p}$-value \\
\hline Mother's age (year) & $28.96 \pm 6.03$ & $28.55 \pm 6.1$ & $0.668^{1}$ \\
\hline Length of hospitalization (day) & $24.75 \pm 12.77$ & $14.09 \pm 9.52$ & $0.001^{1}$ \\
\hline Maternal vitamin D levels (ng/ml) & $16.66 \pm 14.29$ & $21.23 \pm 15.19$ & $0.029^{2}$ \\
\hline Neonatal vitamin D levels (ng/ml) & $11.69 \pm 8.66$ & $17.9 \pm 12.55$ & $0.001^{2}$ \\
\hline Gestational age & $31.57 \pm 1.49$ & $32 \pm 1.63$ & $0.073^{2}$ \\
\hline Apgar (1- minute score) & $5.98 \pm 1.87$ & $7.59 \pm 1.02$ & $0.001^{2}$ \\
\hline Apgar (5- minute score) & $7.51 \pm 1.35$ & $9.72 \pm 9.12$ & $0.001^{2}$ \\
\hline head circumference & $28.84 \pm 2.19$ & $29.9 \pm 1.72$ & $0.002^{2}$ \\
\hline Birth weight (gr) & $1362.6 \pm 347.71$ & $1589.8 \pm 391.75$ & $0.001^{1}$ \\
\hline Cesarean delivery rate & $57.5 \%$ & $63.8 \%$ & $0.418^{3}$ \\
\hline Total & 180 & \multicolumn{2}{|l}{} \\
\hline
\end{tabular}

1: Independent t-test; 2: Mann- Whitney test; 3: Chi- square

The average length of mechanical ventilation and supplemental oxygen for neonates with respiratory distress was $8.53 \pm 6.33$ days. There was no significant correlation between vitamin $\mathrm{D}$ level and length of ventilation $(\mathrm{r}=0.199$, $\mathrm{p}=0.128)$. The prevalence of severe $(10 \mathrm{ng} / \mathrm{ml})$, moderate $(10-20 \mathrm{ng} / \mathrm{ml})$ and mild vitamin D deficiencies were $33.7 \%, 28.7 \%$, and $17.5 \%$ in the control group and the frequencies in preterm infants with respiratory distress were $56.2 \%, 32.5 \%, 6.2 \%$, respectively. The frequency of vitamin D deficiencies was significantly higher in the case group ( $\mathrm{p}=0.001)$. In total, 52 neonates in the case group received one dose and 8 two doses of surfactant. The average level of vitamin $D$ in neonates who received a single dose of surfactant was $10.16 \pm 7.1 \mathrm{mg} / \mathrm{dl}$, and in those who received two doses was $12.42 \pm 6.57 \mathrm{mg} / \mathrm{dl}(\mathrm{p}=0.215)$. Patients' need for oxygen therapy was $7.66 \pm 7.29$ days (139 days). Among 60 infants who underwent ventilation, 34 (42.5\%) neonates received NCPAP, $4(5 \%)$ received NIPPV and in $42(52.5 \%)$ others was done through IPPV. Totally, $90 \%$ of cases in the control group and $70 \%$ of cases in the case group were discharged from the hospital without any complications. Incidence of complications is shown in Table 2. 
Table 2. Incidence of complications in two groups

\begin{tabular}{|l|l|l|l|}
\hline Complications & Case, $(\mathrm{n}=80)$ & Control, $(\mathrm{n}=80)$ & $\mathrm{p}$-value \\
\hline Death & $10(12.5 \%)$ & 0 & $<0.001$ \\
\hline Pneumothorax & $6(7.5 \%)$ & $1(1.2 \%)$ & $<0.001$ \\
\hline Sepsis & $4(5 \%)$ & $3(3.8 \%)$ & $<0.001$ \\
\hline meningitis & $1(1.2 \%)$ & 0 & $<0.001$ \\
\hline Sepsis and meningitis & $2(2.5 \%)$ & 0 & $<0.001$ \\
\hline Seizure & $1(1.2 \%)$ & 0 & $<0.001$ \\
\hline Total & 160 & \\
\hline
\end{tabular}

\section{Discussion}

According to the results of our research, serum levels of vitamin D in neonates with respiratory distress and their mothers was significantly lower compared to the control group. Mean maternal vitamin D levels in neonates with respiratory distress was approximately $5 \mathrm{mg} / \mathrm{dl}$ lower than in neonates without respiratory distress $(\mathrm{p}=0.029)$. These findings indicate that maternal vitamin D level was insufficient for neonates with RDS. In a similar study by Reffat et al. (2014), measurement of the vitamin D level in premature neonates with RDS $(9.52 \pm 2.48 \mathrm{ng} / \mathrm{mL})$ versus healthy preterm infants $(31.25 \pm 1.23 \mathrm{ng} / \mathrm{mL})$ showed that preterm infants with RDS had severe deficiency $(\mathrm{p}<0.001)(17)$. In another study, Cetinkaya et al. (2014) investigated the association between vitamin D deficiency and BPD in premature infants (gestational age $\leq 32$ weeks) who were admitted in NICU with a diagnosis of RDS. In this survey, 25-OH D levels were significantly lower in both infants with BPD and their mothers $(p<0.05)(18)$. It was confirmed that the fetus has no endogenous production of $25-\mathrm{OH} \mathrm{D}$, and is entirely dependent on the transfer from the mother (6), which can explain the association of maternal and neonatal serum vitamin D levels in our study. Human studies revealed that there is a strong relationship between serum concentration of $25-\mathrm{OH} \mathrm{D}$ in the mother and fetal umbilical cord $(19,20)$. The fetus may develop rickets in utero and represent vitamin D deficiency at birth due to severe maternal vitamin D deficiency (21). A low vitamin D level in the mother causes a decreasing transmission of vitamin $\mathrm{D}$ through the placenta and neonates born with low level of vitamin $\mathrm{D}$. A previous study showed that cord blood 25-OH D concentrations had significant association with using vitamin D supplements during pregnancy (22). Marin et al., in a study, showed that treatment of immature fetal rat lung at 18 days of age with active vitamin D increased phospholipid synthesis and also stimulated surfactant secretion (23). In many studies, vitamin D deficiency has been reported to be an important cause of acute respiratory infection in pediatrics (13) and some studies confirmed that vitamin D can improve respiratory status in patients with cystic fibrosis (24). Actually, our study and similar studies have supported the idea that vitamin D deficiency is a risk factor for RDS. According to studies, 1,25 (OH)2D3 causes reduction in glycogen content, increase in surfactant-associated phospholipids and stimulates surfactant secretion in type II pneumocytes isolated from rat lung (5). Nguyen et al. investigated $1,25(\mathrm{OH}) 2 \mathrm{D} 3$ cytosolic binding sites in rat fetal tissues during the last quarter of gestation. According to their findings, lung tissue was one of the main targets for 1,25(OH)2D3 during the fetal period (25). Nguyen et al. in another survey, showed that the vitamin D receptor was observed on the nucleus, cytoplasm and endoplasmic reticulum of type II alveolar cells on the 21 st day of pregnancy, in mouse embryos. In addition, there was an association between vitamin D receptor and maturation of type II alveolar cells, as 1,25(OH)2D3 was active at the intermediate stage of alveolar type II cell differentiation when glycogen content began to decrease. In fact, through activation of vitamin D receptor, glycogen content in the alveolar cells was decreased and intracellular phospholipids were increased (26). Animal studies have shown that vitamin D receptors can be found during late pregnancy (19- 22 days) in rats at precisely the time that type II pneumocytes differentiate, glycogen content was reduced and surfactant was synthesized and secreted $(23,27,28)$. An in vivo study on a BALB/c mouse model of vitamin D deficiency showed that vitamin D deficiency did not affect somatic growth, but lung volume was reduced. They stated that difference between thoracic gas volume (TGV) could be influenced by changes in lung structure (29). Also, it is strongly confirmed by findings of other studies that vitamin D plays an important role in the saccular and alveolar stages of lung development in late pregnancy $(30,31)$. In a review study in 2015, Lykkedegn et al. reported that vitamin D had positive effects on alveolar type II cells, fibroblast proliferation, surfactant synthesis and alveolarization (32). These findings support the hypothesis that vitamin D deficiency is a common and modifiable risk factor for BPD and RDS. The observations confirmed the association between vitamin D deficiency and respiratory distress in preterm infants which is known as rachitic respiratory distress $(3,4)$. Vitamin D effect on airways has also been demonstrated. In a study on mouse emleryo, it showed that vitamin D deficiency causes decrease in TGF-B1 and TGF-B receptor expression. At 8 weeks of postpartum, there were significant increases in 
airway resistance and airway smooth muscle mass, and the volume density of lung parenchyma and alveolar septal volume were lower in these mice. TGF-B level was reduced in Bronchoalveolar Lavage, as well (33). The effect of vitamin $\mathrm{D}$ in production of surfactant has been proven in human studies. All the data support the impact of vitamin $\mathrm{D}$ in the pseudoglandular phase of lung development. In addition, Rehan and Torday have shown that vitamin D had an effect on alveolar epithelial-mesenchymal interactions and inhibit lipofibroblast apoptosis (14). Given dexamethasone and other glucocorticoids commonly used to treat high-risk preterm births, animal studies suggested that vitamin D auxiliary therapy can be used in mothers at risk of preterm birth to prevent RDS. According to reports, dexamethasone had no effect on concentrations of surfactant in the presence of active vitamin D and also, it did not cause increase in lung surfactant secretion $(23,27)$. According to our results, there was no significant difference in the vitamin $\mathrm{D}$ levels between cases who received dexamethasone and those who did not. In the present study, 60 infants underwent ventilation, and the mean length for oxygen therapy was $7.66+7.29$ days. Backstrom et al. compared 39 premature neonates with a gestational age of $<33$ weeks who received vitamin D $200 \mathrm{IU} /$ day or 960 IU/day up to 3 months of age. The number of ventilator days in patients receiving high-dose vitamin $\mathrm{D}$ had a significant decrease $(0$ days versus 4 days $(\mathrm{p}<0.001)$ and also, the time required for supportive oxygen therapy was 2 days versus 14 days $(\mathrm{p}=0.006)$. In addition, respiratory acidosis was more common in the group receiving low doses of vitamin D (34). According to our results, there was a mild to severe vitamin D deficiency in $87.5 \%$ of premature infants with respiratory distress (case group). Also, RDS prevalence in neonates with severe and mild to moderate vitamin D deficiency were $62.5 \%$ and $39.7 \%$, respectively. A study carried out in Ireland reported that vitamin D deficiency was common not only in pregnancy, but also in preterm infants and $78 \%$ of preterm infants with gestational age less than 32 weeks had vitamin D deficiency (8). In the study by Ataseven et al. in 2014 (35), 152 neonates of 29-35 weeks gestation were investigated. In this study, $64 \%$ of neonates had severe deficiency in $25-\mathrm{OH}$ D (less than $10 \mathrm{ng} / \mathrm{mL}), 33 \%$ had moderate deficiency $(10-20 \mathrm{ng} / \mathrm{mL}$ ) and there was a mild deficiency in $3 \%$ of neonates $(20-30 \mathrm{ng} / \mathrm{mL})$. RDS was more common (28\%) in cases of severe vitamin D deficiency compared with neonates with moderate to mild deficiency $(14 \%)(\mathrm{p}<0.05)$. In a study by Fettah et al., among 81 preterm infants with 32 weeks gestational age, the incidence of RDS was $94.7 \%$ in the group of neonates with a vitamin D level less than $5 \mathrm{ng} / \mathrm{ml}$ and in the group with a vitamin D level of 10 to $15 \mathrm{ng} / \mathrm{dl}$ was $89.5 \%$ and the prevalence was $5.4 \%$ in those with vitamin D level higher than $15 \mathrm{ng} / \mathrm{ml}$ (36). The results of these studies, similar to our findings, confirmed the association between vitamin D deficiency and high incidence of RDS in preterm infants. In the present study, 72 neonates in the control group and 56 in the case group were discharged from the hospital without any complications and the others had complications such as sepsis, pneumothorax and death. Higher incidence rate of complications in the case group can be due to the role of vitamin D in the development of innate and adaptive immune system (37). Development and function of regulatory $\mathrm{T}$ cells is stimulated by vitamin D to suppress inappropriate Th1 and Th2 responses against environmental factors such as allergen and infection $(17,23)$. So, vitamin D deficiency can explain the high incidence of sepsis in our study. It also indicated that neonates in the case group had more severe complications which require stronger treatment. Vitamin D deficiency in this group, besides the impact of underlying diseases, has an important role in respiratory infections.

\section{Limitations}

A limitation of this study was small sample size because of the small number of beds in NICUs. Premature infants are more prone to suffer from various problems simultaneously which influence accurate identifications of patients with respiratory problems. Also in our study, matching the neonates for different variables such as gestational age, mothers' age and mothers' vitamin D level was impossible.

\section{Conclusions}

In summary, this study showed that maternal and neonatal vitamin D levels were significantly lower in preterm infants with respiratory distress. Therefore, it can be suggested that low vitamin D levels act as an important factor in development of respiratory distress in preterm infants. Adequate vitamin D intake during pregnancy, transfers to the fetus and contributes in many developmental processes including synthesis and secretion of surfactant that leads to reduction in the incidence and severity of respiratory distress in preterm infants.

\section{Acknowledgments:}

We would like to thank Mashhad University of Medical Sciences, Mashhad, Iran for their financial support of this research. Our thanks also go to Dr. Abbas Boskabadi for sample collection. This article is based on the Dr. Raheleh Faramarzi thesis. 


\section{Conflict of Interest:}

There is no conflict of interest to be declared.

\section{Authors' contributions:}

All authors contributed to this project and article equally. All authors read and approved the final manuscript.

\section{References:}

1) Explore C. National Heart, Lung, and Blood Institute website. 2010.

2) Martin RJ, Fanaroff AA, Walsh MC. Fanaroff and Martin's Neonatal-Perinatal Medicine: Diseases of the Fetus and Infant. 9th ed. Philadelphia: Elsevier Health Sciences; 2010.

3) Phokela SS, Peleg S, Moya FR, Alcorn JL. Regulation of human pulmonary surfactant protein gene expression by 1alpha, 25-dihydroxyvitamin D3. Am J Physiol Lung Cell Mol Physiol. 2005; 289(4): L61726. doi: 10.1152/ajplung.00129.2004. PMID: 15951333.

4) Glasgow JF, Thomas PS. Rachitic respiratory distress in small preterm infants. Arch Dis Child. 1977; 52(4): 268-73. doi: 10.1136/adc.52.4.268. PMID: 860872, PMCID: PMC1544670.

5) Misra M, Pacaud D, Petryk A, Collett-Solberg PF, Kappy M. Vitamin D deficiency in children and its management: review of current knowledge and recommendations. Pediatrics. 2008; 122(2): 398-417. doi: 10.1542/peds.2007-1894. PMID: 18676559.

6) Weisman Y. Maternal, fetal and neonatal vitamin D and calcium metabolism during pregnancy and lactation. Endocr Dev. 2003; 6: 34-49. doi: 10.1159/000072768. PMID: 12964424.

7) Kaushal M, Magon N. Vitamin D in pregnancy: A metabolic outlook. Indian J Endocrinol Metab. 2013; 17(1): 76-82. doi: 10.1159/000072768. PMID: 23776856, PMCID: PMC3659910.

8) McCarthy RA, McKenna MJ, Oyefeso O, Uduma O, Murray BF, Brady JJ, et al. Vitamin D nutritional status in preterm infants and response to supplementation. Br J Nutr. 2013; 110(1): 156-63. doi: 10.1017/s0007114512004722. PMID: 23182428.

9) Goyal R, Zhang L, Blood AB, Baylink DJ, Longo LD, Oshiro B, et al. Characterization of an animal model of pregnancy-induced vitamin D deficiency due to metabolic gene dysregulation. Am J Physiol Endocrinol Metab. 2014; 306(3): E256-66. doi: 10.1152/ajpendo.00528.2013. PMID: 24326417.

10) Chen L, Wilson R, Bennett E, Zosky GR. Identification of vitamin D sensitive pathways during lung development. Respir Res. 2016; 17: 47. doi: 10.1186/s12931-016-0362-3. PMID: 27121020, PMCID: PMC4847230.

11) Saadoon A, Ambalavanan N, Zinn K, Ashraf AP, MacEwen M, Nicola T, et al. Effect of prenatal versus postnatal vitamin D deficiency on pulmonary structure and function in mice. Am J Respir Cell Mol Biol. 2017; 56(3): 383-92. doi: 10.1165/rcmb.2014-0482OC. PMID: 27870560 , PMCID: PMC5359534.

12) Hart PH, Lucas RM, Walsh JP, Zosky GR, Whitehouse AJ, Zhu K, et al. Vitamin D in fetal development: findings from a birth cohort study. Pediatrics. 2015; 135(1): e167-73. doi: 10.1542/peds.2014-1860. PMID: 25511121.

13) Lykkedegn S, Sorensen GL, Beck-Nielsen SS, Christesen HT. The impact of vitamin D on fetal and neonatal lung maturation. A systematic review. Am J Physiol Lung Cell Mol Physiol. 2015; 308(7): L587602. doi: 10.1152/ajplung.00117.2014. PMID: 25595644.

14) Rehan VK, Torday JS, Peleg S, Gennaro L, Vouros P, Padbury J, et al. 1Alpha, 25-dihydroxy-3-epivitamin D3, a natural metabolite of 1alpha, 25-dihydroxy vitamin D3: production and biological activity studies in pulmonary alveolar type II cells. Mol Genet Metab. 2002; 76(1): 46-56. doi: 10.1016/S10967192(02)00022-7. PMID: 12175780.

15) Goldsmith JP, Karotkin E, Keszler M, Suresh G. Assisted Ventilation of the Neonate. Sixth Ed. Elsevier; 2017.

16) Ataseven F, Aygün C, Okuyucu A, Bedir A, Kücük Y, Kücüködük S. Is vitamin d deficiency a risk factor for respiratory distress syndrome? Int J Vitam Nutr Res. 2013; 83(4): 232-7. doi: 10.1024/03009831/a000165. PMID: 25008013.

17) Reffat M. Serum Level of Vitamin D in Neonatal Respiratory Distress. J Clin Investig. 2014; 73(5): 41-8.

18) Cetinkaya M, Cekmez F, Erener-Ercan T, Buyukkale G, Demirhan A, Aydemir G, et al. Maternal/neonatal vitamin D deficiency: a risk factor for bronchopulmonary dysplasia in preterms? J Perinatol. 2015; 35(10): 813-7. doi: 10.1038/jp.2015.88. PMID: 26226242.

19) Nicolaidou P, Hatzistamatiou Z, Papadopoulou A, Kaleyias J, Floropoulou E, Lagona E, et al. Low vitamin D status in mother-newborn pairs in Greece. Calcif Tissue Int. 2006; 78(6): 337-42. doi: 10.1007/s00223006-0007-5. PMID: 16830197. 
20) Maghbooli Z, Hossein-Nezhad A, Shafaei AR, Karimi F, Madani FS, Larijani B. Vitamin D status in mothers and their newborns in Iran. BMC Pregnancy Childbirth. 2007; 7: 1. doi: 10.1186/1471-2393-7-1. PMID: 17295904, PMCID: PMC1808477.

21) Wagner CL, Greer FR. Prevention of rickets and vitamin D deficiency in infants, children, and adolescents. Pediatrics. 2008; 122(5): 1142-52. doi: 10.1542/peds.2008-1862. PMID: 18977996.

22) Belderbos ME, Houben ML, Wilbrink B, Lentjes E, Bloemen EM, Kimpen JL, et al. Cord blood vitamin D deficiency is associated with respiratory syncytial virus bronchiolitis. Pediatrics. 2011; 127(6): e1513-20. doi: 10.1542/peds.2010-3054. PMID: 21555499.

23) Marin L, Dufour ME, Tordet C, Nguyen M. 1,25(OH)2D3 stimulates phospholipid biosynthesis and surfactant release in fetal rat lung explants. Biol Neonate. 1990; 57(3-4): 257-60. doi: 10.1159/000243200. PMID: 2322608.

24) Asadi M, Najarzadeh A, Rajizadeh A. The Role of Vitamin D Supplementation in Cystic Fibrosis: A Systematic Review. SSU_Journals. 2015; 23(1): 1848-57.

25) Nguyen M, Guillozo H, Garabedian M, Balsan S. Lung as a possible additional target organ for vitamin D during fetal life in the rat. Biol Neonate. 1987; 52(4): 232-40. doi: 10.1159/000242714. PMID: 2823916.

26) Nguyen M, Trubert CL, Rizk-Rabin M, Rehan VK, Besancon F, Cayre YE, et al. 1,25-Dihydroxyvitamin D3 and fetal lung maturation: immunogold detection of VDR expression in pneumocytes type II cells and effect on fructose 1,6 bisphosphatase. J Steroid Biochem Mol Biol. 2004; 89-90(1-5): 93-7. doi: 10.1016/j.jsbmb.2004.03.054. PMID: 15225753.

27) Marin L, Dufour ME, Nguyen TM, Tordet C, Garabedian M. Maturational changes induced by 1 alpha,25dihydroxyvitamin D3 in type II cells from fetal rat lung explants. Am J Physiol. 1993; 265(1 Pt 1): L45-52. doi: 10.1152/ajplung.1993.265.1.L45. PMID: 8338181.

28) Mandell E, Seedorf G, Gien J, Abman SH. Vitamin D treatment improves survival and infant lung structure after intra-amniotic endotoxin exposure in rats: potential role for the prevention of bronchopulmonary dysplasia. Am J Physiol Lung Cell Mol Physiol. 2014; 306(5): L420-28. doi: 10.1152/ajplung.00344.2013. PMID: 24414254, PMCID: PMC3949057.

29) Foong RE, Shaw NC, Berry LJ, Hart PH, Gorman S, Zosky GR. Vitamin D deficiency causes airway hyperresponsiveness, increases airway smooth muscle mass, and reduces TGF - $\beta$ expression in the lungs of female BALB/c mice. Physiol Rep. 2014; 2(3): e00276. doi: 10.1002/phy2.276. PMID: 24760528, PMCID: PMC4002254.

30) Phokela SS, Peleg S, Moya FR, Alcorn JL. Regulation of human pulmonary surfactant protein gene expression by 1 $\alpha$, 25-dihydroxyvitamin D3. Am J Physiol Lung Cell Mol Physiol. 2005; 289(4): L617-26. doi: 10.1152/ajplung.00129.2004. PMID: 15951333.

31) Glasgow JF, Thomas PS. Rachitic respiratory distress in small preterm infants. Arch Dis Child. 1977; 52(4): 268-73. doi: 10.1136/adc.52.4.268. PMID: 860872, PMCID: PMC1544670.

32) Lykkedegn S, Sorensen GL, Beck-Nielsen SS, Christesen HT. The impact of vitamin D on fetal and neonatal lung maturation. A systematic review. Am J Physiol Lung Cell Mol Physiol. 2015; 308(7): L587602. doi: 10.1152/ajplung.00117.2014. PMID: 25595644.

33) Foong RE, Shaw NC, Berry LJ, Hart PH, Gorman S, Zosky GR. Vitamin D deficiency causes airway hyperresponsiveness, increases airway smooth muscle mass, and reduces TGF-beta expression in the lungs of female BALB/c mice. Physiol Rep. 2014;2(3):e00276. DOI: 10.1002/phy2.276. PMID: 24760528.

34) Ataseven F, Aygun C, Okuyucu A, Bedir A, Kucuk Y, Kucukoduk S. Is vitamin d deficiency a risk factor for respiratory distress syndrome? Int J Vitam Nutr Res. 2013; 83(4): 232-7. doi: 10.1024/03009831/a000165. PMID: 25008013.

35) Fettah ND, Zenciroglu A, Dilli D, Beken S, Okumus N. Is higher 25-hydroxyvitamin D level preventive for respiratory distress syndrome in preterm infants? Am J Perinatol. 2015; 32(3): 247-50. doi: 10.1055/s0034-1383849. PMID: 25217734.

36) Dancer RC, Parekh D, Lax S, D'souza V, Zheng S, Bassford CR, et al. Vitamin D deficiency contributes directly to the acute respiratory distress syndrome (ARDS). Thorax. 2015; 70(7): 617-24. doi: 10.1136/thoraxjnl-2014-206680. PMID: 25903964, PMCID: PMC4484044. 